\title{
Efficient direct ethanol production from cellulose by cellulase- and cellodextrin transporter-co-expressing Saccharomyces cerevisiae
}

\author{
Ryosuke Yamada ${ }^{1}$, Yuki Nakatani ${ }^{2}$, Chiaki Ogino ${ }^{2}$ and Akihiko Kondo ${ }^{2 *}$
}

\begin{abstract}
Efficient degradation of cellulosic biomass requires the synergistic action of the cellulolytic enzymes endoglucanase, cellobiohydrolase, and $\beta$-glucosidase. Although there are many reports describing consolidation of hydrolysis and fermentation steps using recombinant Saccharomyces cerevisiae that express cellulolytic enzymes, the efficiency of cellulose degradation has not been sufficiently improved. Although the yeast $S$. cerevisiae cannot take up cellooligosaccharide, some fungi can take up and assimilate cellooligosaccharide through a cellodextrin transporter. In this study, a S. cerevisiae strain co-expressing genes for several cell surface display cellulases and the cellodextrin transporter was constructed for the purpose of improving the efficiency of direct ethanol fermentation from phosphoric acid swollen cellulose (PASC). The cellulase/cellodextrin transporter-coexpressing strain produced 1.7-fold more ethanol (4.3 g/L) from PASC during a 72-h fermentation than did a strain expressing cellulase only $(2.5 \mathrm{~g} / \mathrm{L})$. Direct ethanol production from PASC by the recombinant $S$. cerevisiae strain was improved by co-expression of cellulase display and cellodextrin transporter genes. These results suggest that cellulase- and cellodextrin transporter-co-expressing S. cerevisiae could be a promising technology for efficient direct ethanol production from cellulose.
\end{abstract}

Keywords: Bioethanol, Cellulase, Yeast, Cellodextrin transporter, Cell surface display, Cellulose

\section{Introduction}

Dwindling petroleum supplies and growing environmental concerns over petroleum use have led to increasing interest in development of biomass as a feedstock for liquid fuels. Bioethanol produced from biomass resources holds particular promise as an alternative fuel or gasoline extender. Currently, starch-rich biomass serves as the main feedstock used for bioethanol production as it is rapidly hydrolyzed by amylases, resulting in a high yield of glucose. However, lignocellulosic biomasses, such as sugar cane bagasse, corn stover, rice and wheat straw, switchgrass, and poplar, are also regarded as promising starting materials for bioethanol production because they are abundant, inexpensive, renewable, and have favorable environmental properties (Adsul et al. 2011; Sánchez and Cardona 2008).

\footnotetext{
* Correspondence: akondo@kobe-u.ac.jp

${ }^{2}$ Department of Chemical Science and Engineering, Graduate School of Engineering, Kobe University, 1-1 Rokkodaicho, Nada-ku, Kobe, Hyogo 657-8501, Japan

Full list of author information is available at the end of the article
}

Despite these advantages, lignocellulosic biomass is much more expensive to process than grains because of the need for extensive pretreatment and relatively large amounts of cellulase enzymes for efficient hydrolysis. Therefore, more efficient and cost-effective methods for the degradation and fermentation of cellulosic biomass to ethanol are required.

Efficient degradation of cellulosic biomass requires the synergistic action of the cellulolytic enzymes endoglucanase (EG), cellobiohydrolase (CBH), and $\beta$-glucosidase (BGL). Although there are many reports describing relatively low-cost ethanol production from cellulosic material by consolidation of the hydrolysis and fermentation steps using recombinant microorganisms such as the yeast Saccharomyces cerevisiae to express cellulolytic enzymes, the cellulose degradation efficiency has not been sufficiently improved (la Grange et al. 2010; Lynd et al. 2005; Yamada et al. 2013). We previously developed a simple method, designated cocktail $\delta$-integration, to optimize the level of cellulase expression for cellulose degradation (Yamada et al. 2010b). In the cocktail $\delta$-integration method, various 
cellulase expression cassettes are integrated into yeast chromosomes simultaneously in one step, such that strains exhibiting high cellulolytic activity (i.e., strains expressing an optimum ratio of cellulases) can be easily obtained. Use of this method significantly improved the phosphoric acid swollen cellulose (PASC)-degradation activity of cellulase-displaying $S$. cerevisiae, a microorganism that shows tremendous promise for efficient ethanol production from cellulose.

Although yeast such as $S$. cerevisiae cannot take up cellooligosaccharides, some fungi, such as Neurospora crassa, can take up and assimilate cellooligosaccharides through a cellodextrin transporter, facilitating rapid growth on cellulose (Tian et al. 2009). Galazka et al. (2010) were the first to report that expression of the $N$. crassa cellodextrin transporter gene enables $S$. cerevisiae to assimilate cellooligosaccharide. The resulting yeast strain could produce ethanol from cellooligosaccharide directly. Furthermore, addition of a cellulase reagent allowed for simultaneous saccharification and fermentation from cellulose, resulting in more efficient ethanol production compared to the wild type strain.

In this study, a $S$. cerevisiae strain that co-expresses genes for cell surface-displayed cellulases and a cellodextrin transporter was constructed in order to improve the efficiency and yield of direct ethanol production from cellulose. Direct ethanol fermentation from PASC was also examined.

\section{Materials and methods}

\section{Strains and media}

Table 1 summarizes the genetic properties of the strains and plasmids used in this study. Briefly, the host for recombinant DNA manipulations was Escherichia coli strain NovaBlue (Novagen, Madison, WI, USA). Cellodextrin transporter and intracellular BGL were expressed in the haploid yeast strains S. cerevisiae MT8-1 (Tajima et al. 1985) and in previously constructed cellulase surface displaying strain MT8-1/coc $\delta \mathrm{BEC} 1$, which has 8 copies of EGII gene from Trichoderma reesei, 2 copies of CBHII gene from T. reesei, and 1 copy of BGL1 gene from Aspergillus aculeatus (Yamada et al. 2010b). Recombinant yeast strains were screened using synthetic dextrose (SD) medium (6.7 $\mathrm{g} / \mathrm{L}$ yeast nitrogen base without amino acids [Difco Laboratories, Detroit, MI, USA], and $20 \mathrm{~g} / \mathrm{L}$ glucose) supplemented with the appropriate amino acids. PASC was prepared from Avicel PH-101 (Fluka Chemie GmbH, Buchs, Switzerland) as amorphous cellulose (Den Haan et al. 2007). Yeast cells were aerobically cultured in yeast/peptone/dextrose (YPD) medium (10 g/L yeast extract, $20 \mathrm{~g} / \mathrm{L}$ Bacto-peptone [Difco Laboratories], and $20 \mathrm{~g} / \mathrm{L}$ glucose). Aerobic culture proceeded in 1-L flasks containing $500 \mathrm{~mL}$ of medium incubated on a rotary shaker operated at $150 \mathrm{rpm}$. Ethanol fermentation proceeded in YP medium (10 g/L yeast extract and $20 \mathrm{~g} / \mathrm{L}$ Bacto-Peptone) supplemented with $20 \mathrm{~g} / \mathrm{L}$ of either PASC or glucose.

\section{Plasmid construction}

The polymerase chain reaction primers used in this study were summarized in Table 2 . The universal $\delta$ integrative plasmid was constructed as follows. The DNA fragment encoding the promoter sequence of $S$. cerevisiae PGK1, secretion signal sequence of SAG1, and 3 ' half of the $\alpha$-agglutinin gene, including the terminator sequence, was prepared by digesting the plasmid PGK406 AG using the restriction enzymes Xhol/NotI (Yamakawa et al. 2012). The DNA fragment was inserted into the SalI/NotI site of the

Table 1 Characteristics of the E. coli and S. cerevisiae strains and plasmids used in this study

\begin{tabular}{|c|c|c|}
\hline Strains and plasmids & Relevant features & Reference \\
\hline \multicolumn{3}{|l|}{ E. coli strain } \\
\hline Novablue & 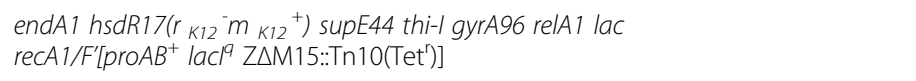 & Novagen \\
\hline \multicolumn{3}{|l|}{ S. cerevisiae yeast strains } \\
\hline MT8-1 & MATa ade leu2 his3 ura3 trp1 & Tajima et al. (1985) \\
\hline MT8-1/coc $\delta B E C 1$ & $\begin{array}{l}\text { MATa ade leu2 his3 ura3, Cocktail } \delta \text {-integration of } \beta \text {-glucosidase, } \\
\text { endoglucanase, and cellobiohydrolase genes }\end{array}$ & Yamada et al. (2010b) \\
\hline MT8-1/8CDTiBGL & $\begin{array}{l}\text { MATa ade leu2 his } 3 \text { trp1, Cocktail } \delta \text {-integration of intracellular } \\
\beta \text {-glucosidase and cellodextrin transporter genes }\end{array}$ & This study \\
\hline 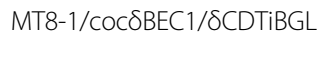 & $\begin{array}{l}\text { MATa ade leu2, Cocktail } \delta \text {-integration of } \beta \text {-glucosidase, endoglucanase, } \\
\text { cellobiohydrolase, intracellular } \beta \text {-glucosidase, and cellodextrin transporter genes }\end{array}$ & This study \\
\hline \multicolumn{3}{|l|}{ Plasmids } \\
\hline p $\delta U-P G C D T$ & URA3, Expression of cellodextrin transporter by $\delta$-integration & This study \\
\hline $\mathrm{p} \delta U-P G i B G L$ & URA3, Expression of intracellular $\beta$-glucosidase by $\delta$-integration & This study \\
\hline p $\delta H-P G i B G L$ & HIS3, Expression of intracellular $\beta$-glucosidase by $\delta$-integration & This study \\
\hline
\end{tabular}




\begin{tabular}{|c|c|}
\hline Primer name & Sequence \\
\hline $\mathrm{CDT}(\mathrm{F})$ & $\begin{array}{l}\text { 5'-ACAACAAATATAAAAAATGTCGTCTCACGGCTCC } \\
\text { CATGACGGGGCCAGCAC-3' }\end{array}$ \\
\hline $\mathrm{CDT}(\mathrm{R})$ & $\begin{array}{l}\text { 5'-GTCGGAACCTCCGCCAGCAACGATAGCTTCGGA } \\
\text { CACATGGCCGTCGGCCT-3' }\end{array}$ \\
\hline UiBGL(F) & $\begin{array}{l}\text { 5'-ACAACAAATATAAAAAGATGAACTGGCGTTCTC } \\
\text { TCCTCCTITCTACCCCTC-3' }\end{array}$ \\
\hline UiBGL(R) & $\begin{array}{l}\text { 5'-GTCGGAACCTCCGCCTTGCACCTTCGGGAGCGC } \\
\text { CGCGTGAAGGGGCAGCT-3' }\end{array}$ \\
\hline $\operatorname{HiBGL}(F)$ & $\begin{array}{l}\text { 5'-AGCTCCACCGCGGTGCGATTTGGGCGCGAATC } \\
\text { CTITATTTGGCTTCACCC-3' }\end{array}$ \\
\hline $\mathrm{HiBGL}(\mathrm{R})$ & $\begin{array}{l}\text { 5'-TCCACTAGTTCTAGAAGCTTIAACGAACGCAGA } \\
\text { ATTITCGAGTTATTAAA-3' }\end{array}$ \\
\hline BGL761(F) & 5'-CTTCCAGGGCTTTGTGATGTC-3' \\
\hline BGL858(R) & 5'-AGGTGATATCGCCAGGCATT-3' \\
\hline EGII968(F) & 5'-GAACAATCGCCAGGCTATCCT-3' \\
\hline EGII1043(R) & 5'-TTGCTGGCACATGTCTTGTATG-3' \\
\hline CBHII387(F) & 5'-GGTTCCCTCTITTATGTGGCTAGA-3' \\
\hline CBHII455(R) & 5'-ATGTCGGCCAAGGTTTGCT-3' \\
\hline CDTI690(F) & 5'-GAGCAACTGGTCATGGCGTAT-3' \\
\hline CDTI761(R) & 5'-AAGACGGAGGACATGACGATAAG-3' \\
\hline
\end{tabular}

plasmid p $\delta U$ (Yamada et al. 2010a), and the resulting plasmid was named p $\delta U P G S e c A G$.

The $\delta$-integrative plasmid for expression of cellodextrin transporter gene CDTI from $N$. crassa was constructed as follows. The DNA fragment encoding CDTI was amplified from N. crassa strain NBRC 6068 cDNA using the primers $\mathrm{CDT}(\mathrm{F})$ and $\mathrm{CDT}(\mathrm{R})$. The fragment was then inserted into the plasmid p $\delta$ UPGSecAG linearized by NheI/SpeI using In-Fusion cloning kit (Takara Bio, Shiga, Japan). The resulting

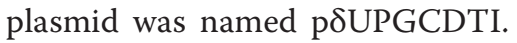

The $\delta$-integrative plasmid for intracellular expression of BGL1 was constructed as follows. The DNA fragment encoding $A$. aculeatus BGL1 gene without its secretion signal sequence was amplified from plasmid p $\delta$ U-PGAGBGL (Yamada et al. 2010b) using the primers $\operatorname{UiBGL}(\mathrm{F})$ and $\operatorname{UiBGL}(\mathrm{R})$. The fragment was then inserted into the plasmid p $\delta$ UPGSecAG linearized by NheI/SpeI using In-Fusion cloning kit. The resulting plasmid was named p $\delta$ UPGiBGL.

Plasmid p $\delta$ HPGiBGL, which was used for intracellular expression of $B G L 1$, was constructed as follows. The gene cassette for intracellular BGL1 expression encoding the $S$. cerevisiae PGK1 promoter, the A. aculeatus BGL1 gene, and the PGK1 terminator was amplified from p $\delta$ UPGiBGL by PCR using the primers HiBGL(F) and HiBGL(R). The resulting fragment was inserted into the plasmid $\mathrm{p} \delta \mathrm{H}$ (Yamada et al. 2010) linearized by NotI using In-Fusion cloning kit. The resulting plasmid was named p $\delta$ HPGiBGL.

\section{Yeast transformation}

Identical amounts (about $20 \mu \mathrm{g}$ ) of each of two comarked $\delta$-integrative plasmids (p $\delta$ UPGCDT and p $\delta$ UPGiBGL, which allow expression of CDT and intracellular BGL1, respectively) were mixed and co-transferred into MT8-1, and the resulting strain was named MT8-1/8CDTiBGL.

A cellulase enzyme expression-optimized strain

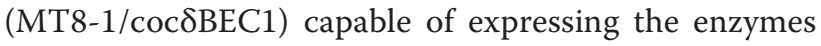
$\mathrm{EG}, \mathrm{CBH}$, and BGL was constructed using the cocktail $\delta$-integration method, as described previously (Yamada et al. 2010b). Identical amounts (about $20 \mu \mathrm{g}$ ) of each of two comarked $\delta$-integrative plasmids (p $\delta$ UPGCDT and p $\delta$ HPGiBGL, which allow expression of CDT and intracellular $B G L 1$, respectively) were mixed and co-transferred into $\mathrm{MT} 8-1 / \operatorname{coc} \delta \mathrm{BEC} 1$, and resulting

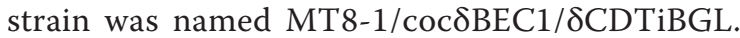

\section{Ethanol fermentation from cellobiose}

Yeast cells were precultured aerobically in YPD medium at $30^{\circ} \mathrm{C}$ for $24 \mathrm{~h}$, harvested by centrifugation at $1,000 \times g$ for $5 \mathrm{~min}$, and then washed twice with distilled water. The wet-cell weight was then determined by harvesting the washed cells by centrifugation at $3,000 \times g$ for $5 \mathrm{~min}$ and weighing the cell pellet (the estimated dry-cell weight for all strains was approximately 0.15-times the wet-cell weight). The cells were then resuspended to an initial cell concentration of $200 \mathrm{~g}$ wet cells/L in $20 \mathrm{~mL}$ of YP medium containing $20 \mathrm{~g} / \mathrm{L}$ of cellobiose. Ethanol fermentation proceeded at $30^{\circ} \mathrm{C}$ for $96 \mathrm{~h}$ with mild agitation in 100-mL closed bottles, each equipped with a siliconized tube and check valve (Sanplatec Corp., Osaka, Japan) as a $\mathrm{CO}_{2}$ outlet. Ethanol, glucose, and cellobiose concentrations were measured simultaneously using a high-performance liquid chromatography (HPLC) system (Shimadzu, Kyoto, Japan) equipped with a Shim-pack SPR-Pb column (Shimadzu) maintained at $80^{\circ} \mathrm{C}$. The column was eluted with water as the mobile phase at a flow rate of $0.6 \mathrm{~mL} / \mathrm{min}$, and the eluate was monitored using a refractive index detector (Shimadzu, RID10A). Culture broth was centrifuged at $14,000 \times g$ for $10 \mathrm{~min}$, and a sample of the resulting supernatant was analyzed by HPLC.

\section{PASC degradation activity}

To examine PASC degradation activity, yeast cells were cultivated in YPD medium for $24 \mathrm{~h}$ at $30^{\circ} \mathrm{C}$, collected by centrifugation at $1,000 \times \mathrm{g}$ for $5 \mathrm{~min}$ at $4^{\circ} \mathrm{C}$, and then washed twice with distilled water. Washed cells were added to a $1-\mathrm{mL}$ solution of $5 \mathrm{~g} / \mathrm{L}$ PASC in $50 \mathrm{mmol} / \mathrm{L}$ sodium citrate buffer ( $\mathrm{pH}$ 5.0). After the hydrolysis reaction was allowed to proceed for $6 \mathrm{~h}$ at $50^{\circ} \mathrm{C}$, the supernatant was collected by centrifugation for $5 \mathrm{~min}$ at $10,000 \times g$ at $4^{\circ} \mathrm{C}$ to 
remove cells and debris, and the concentration of the glucose produced was measured using a Glucose CII Test (Wako Pure Chemical Industries, Osaka, Japan). One unit of PASC degradation activity was defined as the amount of enzyme producing $1 \mu \mathrm{mol}$ glucose $/ \mathrm{min}$ at $50^{\circ} \mathrm{C}$ and $\mathrm{pH} 5.0$.

\section{Quantification of cellulolytic enzyme gene transcription using real-time PCR}

The transcription level of each cellulase gene as well as that of the CDT gene was quantified using real-time reverse transcription (RT)-polymerase chain reaction (PCR). Total RNA was isolated from yeast cells cultivated in YPD medium for $24 \mathrm{~h}$ at $30^{\circ} \mathrm{C}$ using a RiboPure Yeast Kit (Ambion, Austin, TX, USA), and cDNA was then synthesized from total RNA using a ReverTra Ace qPCR RT Kit (Toyobo, Osaka, Japan). Real-time RT-PCR using synthesized cDNA as a template was performed using a Stratagene MX3000P qPCR system (Agilent/Stratagene, La Jolla, CA, USA) with four sets of PCR primers (BGL761(F) and BGL858(R), EGII968(F) and EGII1043(R), CBHII387 (F) and CBHII455(R), and CDTI690(F) and CDTI761(R)) and Thunderbird SYBR qPCR Mix (Toyobo). The primers BGL761(F) and BGL858(R) were constructed for detecting both intracellular $B G L 1$ gene transcription and surface displayed BGL1 gene transcription. Transcription levels of the target genes were normalized to the housekeeping gene PGK1 using a standard curve method.

\section{Ethanol fermentation from PASC}

Yeast cells were precultured aerobically in YPD medium at $30^{\circ} \mathrm{C}$ for $72 \mathrm{~h}$, harvested by centrifugation at $1,000 \times g$ for $5 \mathrm{~min}$, and then washed twice with distilled water. The wet-cell weight was then determined by harvesting the washed cells by centrifugation at $3,000 \times g$ for $5 \mathrm{~min}$ and weighing the cell pellet. The cells were then resuspended to an initial cell concentration of 200-g wet cells/L in $20 \mathrm{~mL}$ of YP medium containing $20 \mathrm{~g} / \mathrm{L}$ of PASC. Ethanol fermentation proceeded at $37^{\circ} \mathrm{C}$ for $96 \mathrm{~h}$ with mild agitation in $100-\mathrm{mL}$ closed bottles, each equipped with a siliconized tube and check valve as a $\mathrm{CO}_{2}$ outlet. Ethanol concentration was determined using a gas chromatograph (model GC-2010; Shimadzu) equipped with a flame ionization detector and a Durabond Free Fatty Acid Phase (DB-FFAP) column (60 $\mathrm{m} \times 0.25 \mathrm{~mm}$ internal diameter; $0.5 \mu \mathrm{m}$ film thickness; Agilent Technologies, Palo Alto, CA, USA). Helium was used as the carrier gas. The injection volume and split ratio were adjusted to $1 \mu \mathrm{L}$ and 1:50, respectively. The column temperature was programmed to increase from $40^{\circ} \mathrm{C}$ to $170^{\circ} \mathrm{C}$ with a linear gradient of $10^{\circ} \mathrm{C} / \mathrm{min}$.

\section{Results}

\section{Co-expression of cellodextrin transporter and}

$\beta$-glucosidase

Ethanol fermentation from cellobiose was carried out in order to confirm functional intracellular expression of cellodextrin transporter and $\beta$-glucosidase. As shown in Figure 1 , the cellodextrin transporter/ $\beta$-glucosidase-coexpressing strain consumed $18.5 \mathrm{~g} / \mathrm{L}$ of cellobiose and produced $6.4 \mathrm{~g} / \mathrm{L}$ of ethanol during a 12-h fermentation. The ethanol yield reached $61 \%$ of the theoretical yield. In contrast, no detectable ethanol was produced from cellobiose by the wild type strain during a 24-h fermentation. These results confirmed functional intracellular expression of cellodextrin transporter and $\beta$-glucosidase gene.

\section{Cellulase activity of the cellodextrin transporter/cellulase- co-expressing strain}

Degradation of PASC was examined in order to determine the effect of cellodextrin transporter expression on the cellulase activity of the cellodextrin transporter/cellulaseco-expressing stain. As shown in Figure 2, the PASC degradation activity of the cellodextrin transporter/cellulaseco-expressing strain (101.5 mU/g-wet cells) was almost the same as that of the cellulase-expressing strain (101.6 mU/g-wet cells). Thus, the effect of cellodextrin transporter expression on the activity of the cell surface cellulase was negligible.

\section{Quantification of the transcription level of cellulolytic enzyme genes using real-time RT-PCR}

Real-time RT-PCR was carried out in order to confirm the effect of cellodextrin transporter expression on the

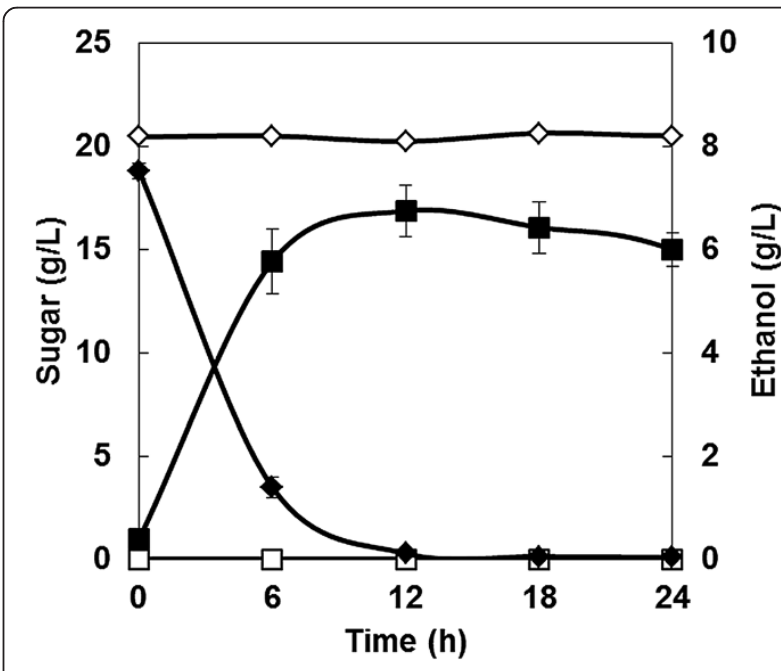

Figure 1 Time course of ethanol production from cellobiose by engineered strains. Diamonds = cellobiose; squares $=$ ethanol; open symbols $=$ MT8-1; closed symbols $=$ MT8-1/8CDTiBGL. Data are averages from three independent experiments (error bars represent SE). 


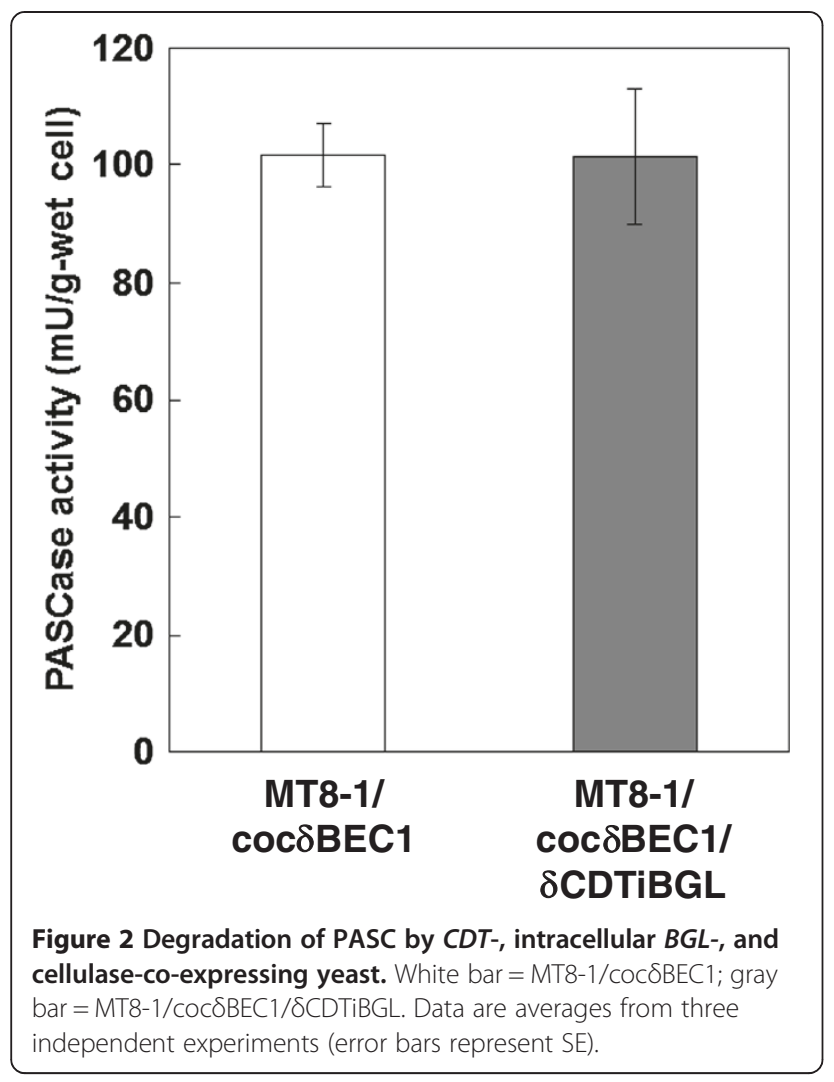

transcription level of each cellulase gene. As shown in Figure 3, the level of transcription of the EGII and $C B H I I$ genes in the cellulase-expressing strain (5.21 and 1.90, respectively) was almost same as that in the cellodextrin transporter/cellulase-co-expressing strain (5.11 and 1.49, respectively). In contrast, the level of

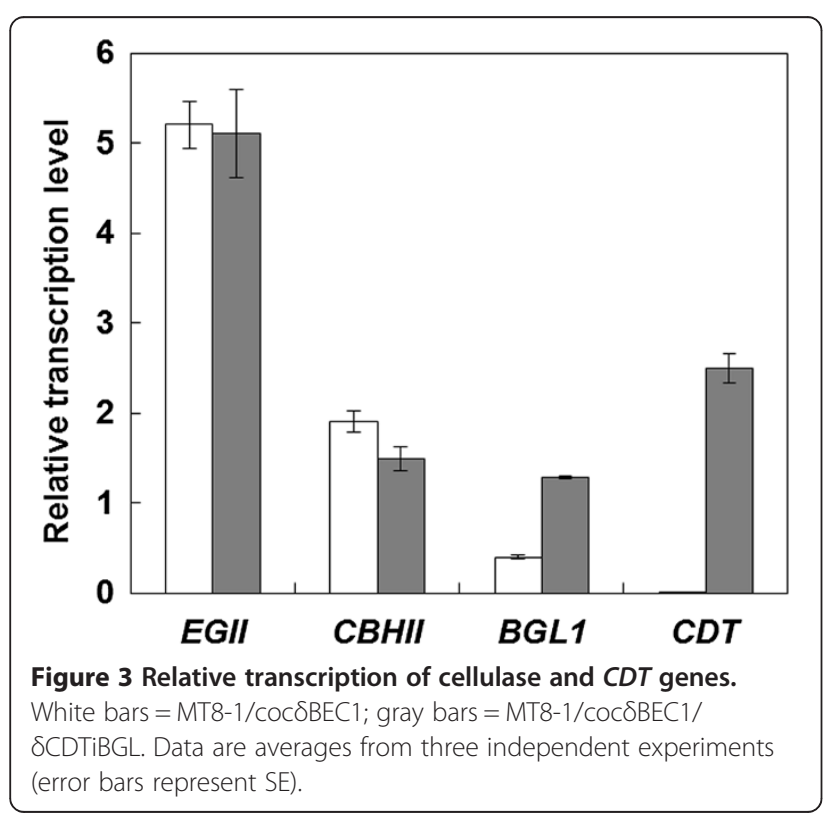

BGL1 transcription in the cellulase-expressing strain (0.40) was 3.2-fold lower than that in the cellodextrin transporter/cellulase-co-expressing strain (1.29). In addition, the transcription of $C D T$ was detected only in the cellodextrin transporter/cellulase-co-expressing strain.

\section{Ethanol production from PASC by the cellodextrin transporter/cellulase-co-expressing yeast strain}

Direct ethanol production from PASC was carried out in order to evaluate the effect of co-expression of cellulases and the cellodextrin transporter on direct ethanol production from cellulose. As shown in Figure 4, the cellodextrin transporter/cellulase-co-expressing strain produced $4.3 \mathrm{~g} / \mathrm{L}$ of ethanol from PASC during a 72-h fermentation, a 1.7-fold higher level of production than that of the cellulase-expressing strain $(2.5 \mathrm{~g} / \mathrm{L})$. Ethanol yield by the cellodextrin transporter/cellulase-co-expressing strain reached $37 \%$ of the theoretical yield.

\section{Discussion}

In this study, a S. cerevisiae strain co-expressing cellodextrin transporter and cellulase genes was constructed. This strain showed a higher level of ethanol production from PASC than a strain expressing only cellulase genes.

Galazka et al. (2010) were the first to report expression of the $N$. crassa cellodextrin transporter and $\beta$-glucosidase genes in $S$. cerevisiae, and subsequent ethanol production from cellobiose by that yeast strain. In this study, $N$. crassa cellodextrin transporter and $A$. aculeatus $\beta$-glucosidase, an enzyme with high specific activity (Decker et al. 2000;

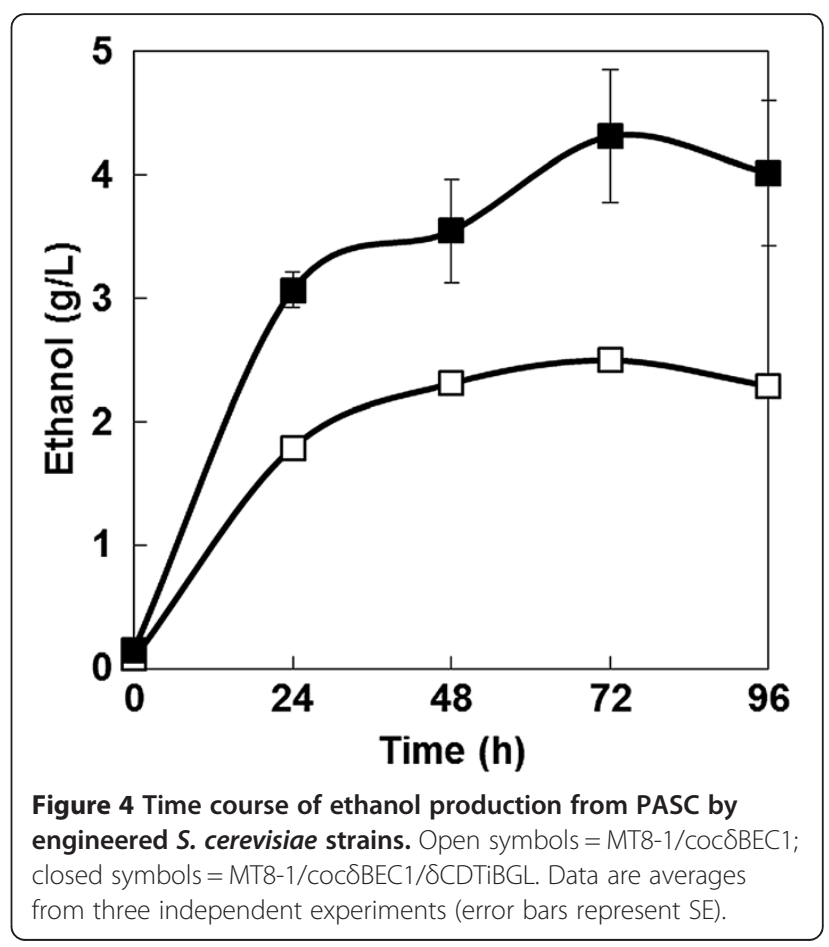


Takada et al. 1998), were co-expressed in S. cerevisiae, and this strain also produced ethanol. Intracellular expressed $\beta$-glucosidase activity was not detected in the medium (data not shown). Thus, intracellular expression of $\beta$-glucosidase could be effectively achieved. Large amounts of cellulolytic enzymes including cellulase and $\beta$-glucosidase are required for efficient degradation of cellulose. Thus, it would be important for efficient direct ethanol production from cellulose to express cellulolytic enzymes, which have high specific activity, such as $A$. aculeatus $\beta$-glucosidase used in this study.

As shown in Figure 3, the level of BGL1 transcription in the cellulase/cellodextrin transporter-co-expressing strain was higher than in the strain expressing only cellulase due to the fact that the genes encoding both the intracellular and extracellular forms of BGL are transcribed in the cellulase/cellodextrin transporter-co-expressing strain. Both intracellular and extracellular forms of $B G L$ gene transcription were detected by the same set of primers BGL761(F) and BGL858(R). Although the cellulase/cellodextrin transporter-co-expressing strain expressed cellodextrin transporter and intracellular BGL, the level of EGII and CBHII transcription did not decrease in comparison to the strain expressing only cellulase. This result indicates the co-expressing strain has sufficient capacity to express more cellulolytic enzyme genes. Thus, increasing the number of integrated genes and/or diploidization could be promising strategies for improving cellulolytic activity in yeast (Yamada et al. 2009).

Although the PASC degradation activity and level of cellulase gene transcription of the cellulase/cellodextrin transporter-co-expressing strain was very similar to that of the strain expressing cellulase only (Figures 2 and 3), it produced more ethanol from PASC than did the strain expressing only cellulase (Figure 4). One explanation for this result could be that product inhibition was avoided. Gruno et al. (2004) and Xiao et al. (2004) reported that the activity of endoglucanase and $\beta$-glucosidase enzymes is inhibited by the respective products of these enzymes (cellobiose and glucose, respectively). Although the concentration of cellobiose and glucose were lower than the detection limit in this study, their concentrations could be decreased by introducing a bypass which is cellodextrin assimilating pass way by cellodextrin transporter and intracellular $\beta$-glucosidase. Product inhibition could thus be avoided and ethanol productivity improved. This product inhibition avoiding effect is in accordance with a previous study involving amylolytic yeast (Yamakawa et al. 2010). The authors of that report indicated that production of ethanol from raw starch can be improved by introducing a maltose transporter as a bypass. Galazka et al. (2010) used cellodextrin transporterexpressing S. cerevisiae for simultaneous saccharification and fermentation from cellulose with addition of cellulase.
In contrast, in this study, the cellodextrin transporter was co-expressed with three different cellulase genes. As a result, direct ethanol production from cellulose was improved without the need for addition of cellulase. Thus, the use of $S$. cerevisiae that co-express cellodextrin transporter and cellulase genes is a promising strategy for direct ethanol fermentation from cellulose.

In conclusion, the ability of recombinant $S$. cerevisiae to ferment PASC was improved by engineering the organism to co-express genes encoding cell surface-displayed cellulases and the cellodextrin transporter gene. The ethanol production rate and amount of ethanol produced in this study were low compared to industrial production levels. However, construction of industrial cellulolytic yeast might be achieved in the future by combining techniques such as yeast diploidization with strategies to improve cellulolytic activity, such as optimizing the expression level of each cellulolytic enzyme gene (Yamada et al. 2010b, 2011).

\section{Competing interests}

The authors declare that they have no competing interests.

\section{Authors' contributions}

RY and YN wrote the paper. YN designed and performed the experiments. $\mathrm{CO}$ and AK commented and supervised on the manuscript. All authors read and approved the final manuscript.

\section{Acknowledgements}

This work was supported in part by the Environment Research and Technology Development Fund of the Ministry of the Environment, Japan; and by the New Energy and Industrial Technology Development Organization (NEDO) of Japan; and by Special Coordination Funds for Promoting Science and Technology, Creation of Innovation Centers for Advanced Interdisciplinary Research Areas (Innovative Bioproduction Kobe), MEXT, Japan.

\section{Author details}

'Organization of Advanced Science and Technology, Kobe University, 1-1 Rokkodaicho, Nada-ku, Kobe, Hyogo 657-8501, Japan. ²Department of Chemical Science and Engineering, Graduate School of Engineering, Kobe University, 1-1 Rokkodaicho, Nada-ku, Kobe, Hyogo 657-8501, Japan.

Received: 3 May 2013 Accepted: 18 June 2013

Published: 24 June 2013

\section{References}

Adsul MG, Singhvi MS, Gaikaiwari SA, Gokhale DV (2011) Development of biocatalysts for production of commodity chemicals from lignocellulosic biomass. Bioresour Technol 102:4304-4312

Decker CH, Visser J, Schreier P (2000) Beta-glucosidases from five black Aspergillus species: study of their physico-chemical and biocatalytic properties. J Agric Food Chem 48:4929-4936

Den Haan RS, Rose H, Lynd LR, van Zyl WH (2007) Hydrolysis and fermentation of amorphous cellulose by recombinant Saccharomyces cerevisiae. Metab Eng 9:87-94

Galazka JM, Tian C, Beeson WT, Martinez B, Glass NL, Cate JH (2010) Cellodextrin transport in yeast for improved biofuel production. Science 330:84-86

Gruno M, Väljamäe P, Pettersson G, Johansson G (2004) Inhibition of the Trichoderma reesei cellulases by cellobiose is strongly dependent on the nature of the substrate. Biotechnol Bioeng 86:503-511

la Grange DC, den Haan R, van Zyl WH (2010) Engineering cellulolytic ability into bioprocessing organisms. Appl Microbiol Biotechnol 87:1195-1208

Lynd LR, van Zyl WH, McBride JE, Laser M (2005) Consolidated bioprocessing of cellulosic biomass: an update. Curr Opin Biotechnol 16:577-583

Sánchez OJ, Cardona CA (2008) Trends in biotechnological production of fuel ethanol from different feedstocks. Bioresour Technol 99:5270-5295 
Tajima M, Nogi Y, Fukasawa T (1985) Primary structure of the Saccharomyces cerevisiae GAL7 gene. Yeast 1:67-77

Takada G, Kawaguchi T, Sumitani J, Arai M (1998) Expression of Aspergillus aculeatus No. F-50 cellobiohydrolase I (cbhl) and beta-glucosidase 1 (bgl1) genes by Saccharomyces cerevisiae. Biosci Biotechnol Biochem 62:1615-1618

Tian C, Beeson WT, lavarone AT, Sun J, Marletta MA, Cate JH, Glass NL (2009) Systems analysis of plant cell wall degradation by the model filamentous fungus Neurospora crassa. Proc Natl Acad Sci U S A 106:22157-22162

Xiao Z, Zhang X, Gregg DJ, Saddler JN (2004) Effects of sugar inhibition on cellulases and beta-glucosidase during enzymatic hydrolysis of softwood substrates. Appl Biochem Biotechnol 113-116:1115-1126

Yamada R, Bito Y, Adachi T, Tanaka T, Ogino C, Fukuda H, Kondo A (2009) Efficient production of ethanol from raw starch by a mated diploid Saccharomyces cerevisiae with integrated a-amylase and glucoamylase genes. Enzyme Microb Technol 44:344-349

Yamada R, Tanaka T, Ogino C, Fukuda H, Kondo A (2010a) Novel strategy for yeast construction using delta-integration and cell fusion to efficiently produce ethanol from raw starch. Appl Microbiol Biotechnol 85:1491-1498

Yamada R, Taniguchi N, Tanaka T, Ogino C, Fukuda H, Kondo A (2010b) Cocktail delta-integration: a novel method to construct cellulolytic enzyme expression ratio-optimized yeast strains. Microb Cell Fact 14:32

Yamada R, Taniguchi N, Tanaka T, Ogino C, Fukuda H, Kondo A (2011) Direct ethanol production from cellulosic materials using a diploid strain of Saccharomyces cerevisiae with optimized cellulase expression. Biotechnol Biofuels 4:8

Yamada R, Hasunuma T, Kondo A (2013) Endowing non-cellulolytic microorganisms with cellulolytic activity aiming for consolidated bioprocessing. Biotechnol Adv. doi:10.1016/..biotechadv.2013.02.007

Yamakawa S, Yamada R, Tanaka T, Ogino C, Kondo A (2010) Repeated batch fermentation from raw starch using a maltose transporter and amylase expressing diploid yeast strain. Appl Microbiol Biotechnol 87:109-115

Yamakawa S, Yamada R, Tanaka T, Ogino C, Kondo A (2012) Repeated fermentation from raw starch using Saccharomyces cerevisiae displaying both glucoamylase and a-amylase. Enzyme Microb Technol 50:343-347

doi:10.1186/2191-0855-3-34

Cite this article as: Yamada et al:: Efficient direct ethanol production

from cellulose by cellulase- and cellodextrin transporter-co-expressing Saccharomyces cerevisiae. AMB Express 2013 3:34

\section{Submit your manuscript to a SpringerOpen ${ }^{\circ}$ journal and benefit from:}

- Convenient online submission

- Rigorous peer review

- Immediate publication on acceptance

- Open access: articles freely available online

- High visibility within the field

- Retaining the copyright to your article

Submit your next manuscript at $\boldsymbol{~ s p r i n g e r o p e n . c o m ~}$ 